\title{
Identification of Risk Factors for Postoperative Cerebrospinal Fluid Leakage and Comparison of Two Alternative Dural Augmentation Techniques in Posterior Fossa and Spinal Surgeries
}

\author{
Muhammed Taha ESER ${ }^{1}$, Sahin HANALIOGLU1, Mehmet Ziya CETINER ${ }^{1}$, Samet DINC ${ }^{1}$, Halil Olgun PEKER ${ }^{2}$, \\ Mehmet SORAR ${ }^{1}$, Habibullah DOLGUN ${ }^{1}$, Erhan TURKOGLU ${ }^{1}$ \\ ${ }^{1}$ Health Sciences University, Diskapi Yildirim Beyazit Training and Research Hospital, Department of Neurosurgery, Ankara, Turkey \\ ${ }^{2}$ Health Sciences University, Istanbul Okmeydani Training and Research Hospital, Department of Neurosurgery, Istanbul, Turkey
}

Corresponding author: Erhan TURKOGLU drmet122@yahoo.com

\section{ABSTRACT}

AIM: To investigate comparative efficacy of a novel absorbable adhesive membrane (TissuePatchDural "TM "TPD") and a fibrin glue (Tisseel "T") in reducing cerebrospinal fluid (CSF) leaks after posterior fossa and spinal procedures, and also to identify potential risk factors for CSF leakage.

MATERIAL and METHODS: This is a single-center, retrospective cohort study of 123 consecutive posterior fossa ( $n=77$ ) and spinal $(n=46)$ surgeries. Patients were grouped based on dural sealants used 2-group comparison: TPD ( $n=56)$ vs. no-TPD ( $n=67)$ and 3-group comparison: $T$ only $(n=43)$, TPD only ( $n=32)$ vs TPD+T $(n=35)$.

RESULTS: Mean age was $38.9 \pm 22.2$ years (62 males, 61 females). Baseline characteristics were similar between groups. Neither 2-group (TPD: $10.4 \%$ vs no-TPD: $8.9 \%$; $p=0.778$ ) nor 3 -group (T: 9.3\% vs TPD: $6.3 \%$ vs TPD+T: $14.3 \%$; $p=0.539$ ) comparisons revealed a significant difference in postoperative CSF leakage rates. Multivariate analysis showed that diagnosis (non-tumoral vs. tumor) (OR: 5.487; 95\% Cl: 1.118-26.937; $p=0.036$ ); previous surgery (OR: 9.268; 95\% Cl: 1.911-44.958; $p=0.006$ ), postoperative hydrocephalus (OR: 5.456; 95\% Cl: 1.250-23.821; $p=0.024$ ) were independent predictors of postoperative CSF leakage.

CONCLUSION: TissuePatchDural ${ }^{\mathrm{TM}}$ is a novel dural sealant patch which can be safely used to reinforce dural closure in posterior fossa and spinal surgeries, and its efficacy is comparable to widely used fibrin glue (Tisseel). Non-tumoral pathologies, previous surgery, and postoperative hydrocephalus appear to be independent risk factors for postoperative CSF leakage.

KEYWORDS: Cerebrospinal fluid, Leakage, Dural sealant, Patch, Fibrin glue

\section{INTRODUCTION}

A chieving watertight closure of dura mater is critical in most neurosurgical procedures as cerebrospinal fluid (CSF) leakage is a common and potentially harmful complication. Failure to prevent CSF leaks after dural closure may increase the risk of meningitis, compromise wound healing and cause disturbances of CSF dynamics $(1,4)$. These potential complications, in turn, lead to increased morbidity, prolonged hospital stay, repeated surgical interventions, higher economical costs and frustration to both patients and health professionals $(5,9,10,12)$.
Muhammed Taha ESER (1): 0000-0002-1391-4341 Sahin HANALIOGLU (D): 0000-0003-4988-4938 Mehmet Ziya CETINER (1) : 0000-0003-4448-4759
(D) : 0000-0002-8090-3335

: : 0000-0001-9079-8885

D : 0000-0002-6933-7627
Habibullah DOLGUN (1): 0000-0002-1513-2044 Erhan TURKOGLU (1D): 0000-0001-7044-617X 
The risk of CSF leakage is dependent on several factors as outlined in many studies in the literature. One of the most important factors is the location of the surgery. Posterior fossa and intradural spinal surgeries have higher risk of postoperative CSF leakage due to increased CSF pressure and flow inherently related to the these surgical sites. Besides, patient-related factors such as age, diabetes mellitus, systemic infections and malignancies, previous surgery and radiation therapy, chemotherapy and immunosuppressants, and underlying pathological processes may have significant effect on dural closure and healing, and thus, the incidence of CSF leaks (10).

Primary aim in dural closure, particularly in high-risk cases in which cisternal and/or ventricular opening is performed, is to suture dura in a watertight fashion. However, this may not be sufficient and dural closure may need to be augmented with sealing agents and materials. Various dural sealants have been developed and used for this purpose. Several reports, albeit mostly consisting of non-randomized studies, have showed that use of sealants reduce the incidence of CSF leaks in supratentorial, infratentorial, transsphenoidal, skull base and spinal operations. Therefore, nowadays, the use of dural sealants is a widely adopted practice in especially highrisk posterior fossa surgeries in which CSF leak rates may be as high as $32 \%$.

In this study, we aimed to investigate comparative efficacy of a novel absorbable adhesive membrane (TissuePatchDural ${ }^{\mathrm{TM}}$ ) and a commonly used fibrin glue (Tisseel) in reducing CSF leaks after posterior fossa and spinal procedures. In addition, we identified risk factors for CSF leak in this single-center, retrospective cohort study.

\section{MATERIAL and METHODS}

\section{Patients and Selection Criteria}

This is a single-center, retrospective cohort study involving patients who underwent elective operation for posterior fossa or spinal pathologies in two-year period (June 2016-May 2018). Informed consent was obtained from all patients. Inclusion criteria were; i) elective surgery, ii) procedures involving dural and arachnoidal opening, iii) patients with complete pre, intraand post-operative clinical and radiological data. Exclusion criteria were; i) supratentorial craniotomy, ii) patients with ischemic or hemorrhagic complications requiring early surgery and removal of dural sealant, ii) incomplete data or indeterminate postoperative CSF leak status. Of 148 patients retrieved from institutional database for the study period, 123 met both inclusion and exclusion criteria.

\section{Study Groups}

We grouped the patients based on their dural augmentation status. To this end, we first determined whether each individual case had Tisseel (T) and/or TissuePatchDural ${ }^{\mathrm{TM}}$ (TPD) applied during surgery. This yielded four subgroups as follows: No sealant $(n=13)$, Tisseel only $(n=43)$, TissuePatchDural ${ }^{\mathrm{TM}}$ only $(n=32)$ and TissuePatchDural ${ }^{\mathrm{TM}}+$ Tisseel $(n=35)$. Later we had two different grouping schemes for statistical analyses: Two- group and Three-group comparisons. In two-group analysis, we compared TPD group with non-TPD group regardless of their Tisseel status. In three-group analysis, we excluded no sealant group due to its small number of patients, and included the other three subgroups in the analysis.

\section{Dural Sealants and Surgical Technique}

\section{TissuePatchDural ${ }^{T M}$}

TissuePatchDural ${ }^{\mathrm{TM}}$ (Tissuemed Ltd.) is an entirely synthetic, self-adhesive, absorbable, transparent film serving as a surgical sealant and barrier (Figure $1 \mathrm{~A})$. It is a multilayered membrane incorporating structural [poly (lactide-co-glycolide)] and adhesive (Terpolymer) absorbable components. Once adhered to dura in a few minutes, it stays in position and slowly degrades until substantially reabsorbed in about 50 days.

\section{Tisseel}

Tisseel is commercially available fibrin glue and consists of human-derived fibrinogen and thrombin, and has been designed as a topical hemostatic agent to stop low level of brisk arterial and venous bleeding. As other fibrin sealants, it acts both as hemostatic and sealing agent due to its physical and chemical properties. Its liquid form allows easy application, particularly in difficult-to-access areas, but its preparation is time-consuming and some patients may have adverse reactions to it.

\section{Dural closure and duraplasty}

After craniotomy (posterior fossa) or laminectomy (spinal), dura mater was primarily closed with 3-0 silk sutures. In case of small $(<5 \mathrm{~mm})$ dural defects, muscle grafts were used to plug the defect. In case of overt defects $(>5 \mathrm{~mm}$ ) or large dural tissue loss, duraplasty with autograft (galea or periosteum), xenograft or synthetic dural grafts were performed. To confirm watertight closure, surgical cavity was subdurally irrigated with saline before tying last suture in the superior margin of dural incision and a Valsalva maneuver was performed after the last stitch. If a high-volume CSF leak is evident, then additional muscle or periosteal grafts were stitched to reinforce the dural closure. If a low-volume or no CSF leak is observed, then the dural sealants were applied to cover dural sutures depending on surgeon's preference. In addition, when mastoid air cells were opened, muscle and/or wax were used as primary sealants.

\section{Dural augmentation}

Before dural augmentation with sealants, maximal care was taken to keep dural surface as dry as possible with removing excesive blood and fluid. In Tisseel only group, fibrin glue is directly applied over dural sutures and left in place. In TPD only group, first, TPD was cut to give proper shape if required before removing from the protector (Figure 1B). It was handled with dry instruments and placed carefully over the dura within craniotomy site. It is supported with cottonoids to correctly position and allow for maximal contact with underlying dura. Care was taken to prevent its margins to contact the surrounding bone or muscle instead of dura as this 
compromised its adherence to dura (Figure 1C, D). A gentle pressure with fingers and/or moist swabs was applied for at least 60 seconds. In TPD+T group, after placement of TPD as described above, Tisseel fibrin glue was applied over and around the TPD membrane to further reinforce attachment of TPD to underlying dura. After dural augmentation, a second Valsalva maneuver was performed to reassure watertight closure. Bone flap was replaced if indicated and muscle, fascia, subcutaneous tissue and skin were closed in anatomical layers. No drain was used in posterior fossa surgeries. A subfascial drain was placed in spinal procedures. Prophylactic antibiotics were administered during and after the surgery. Postoperatively, ifpseudomeningocele occurred, first intervention was pressure dressing with or without puncture depending on volume and tension of the collection. In case of incisional leak, skin opening was sutured and pressure dressing was applied. If the CSF leak persisted, further interventions such as lumbar punctures, lumbar drainage and wound revisions were considered.

\section{Data Collection}

Data were obtained through a retrospective review of patient charts and electronic health records by two independent neurosurgeons who were not involved in performing surgical procedures. Demographic, clinical and radiological data collected included age, sex, location, diagnosis/pathology, risk factors including comorbidities, previous surgery and radiotherapy, pre and postoperative hydrocephalus, dura closure technique (primary suturing, duraplasty with galeal graft, xenograft or synthetic grafts), intraoperative use of Tisseel and TPD, postoperative CSF fistula (closed "pseudomeningocele" or open "incisional CSF leak"), additional intervention (puncture, lumbar drain, shunt etc.), other complications and hospital stay.

\section{Statistical Analyses}

Statistical analyses were performed using SPSS 22.0 software (IBM, New York). Data are presented as mean \pm standard deviation for parametric, median (range) for non-parametric continuous variables, and as frequency or percentage for categorical variables. Two-group comparisons were performed by Chi-square and Fisher's exact tests for categorical and Student's t-test for parametric variables. Three-group comparisons were done using Chi-square test for categorical and by One-way ANOVA with Bonferroni correction for parametric variables. Logistic regression was performed to test the effect of potential predictors of CSF fistula. All factors with $p$ value $<0.15$ in the univariate analysis,
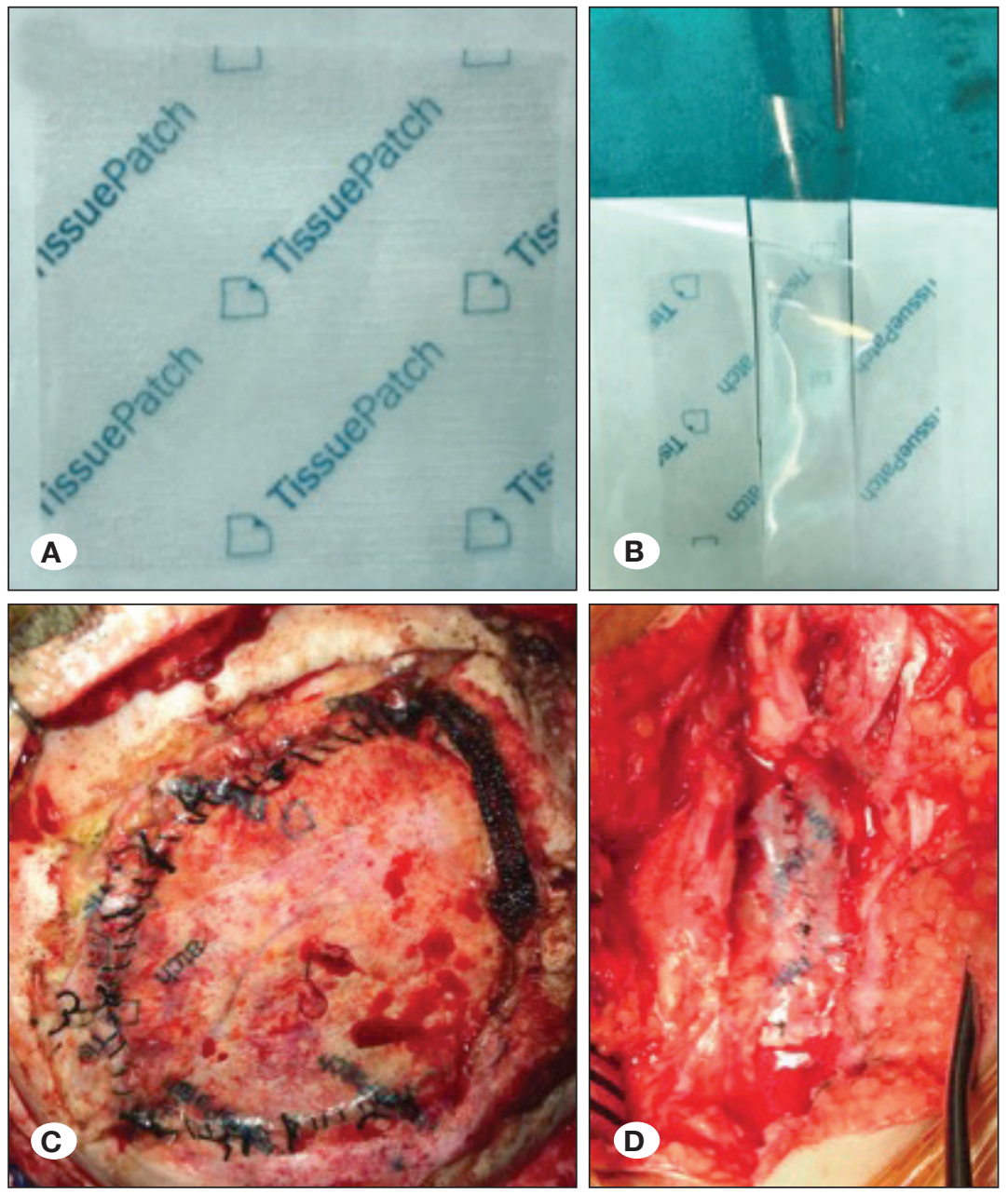

Figure 1: Intraoperative application of TissuePatchDural $^{\text {TM }}$ (TPD). A) $50 \times 50 \mathrm{~mm}$ sterile TPD patch in its protector pouch. B) It can be cut as desired to accurately fit to dural incision size and then patch is pulled away from the pouch and handled gently with dry instruments. TPD can be applied to $\mathbf{C}$ ) craniotomy site (over cranial durotomy), and D) laminectomy site (or spinal durotomy) after dural closure. 
but omitting those with high degree of inter-correlation, were incorporated into the multivariate model. A p value $<0.05$ was considered statistically significant.

\section{RESULTS}

\section{Baseline (Preoperative) Characteristics}

A summary of baseline characteristics of 123 patients ispresented in Table I. Mean age was $38.9 \pm 22.2$ years (median 41 , range 1-81 years). About one-fourth of the patients (23.6\%) were under 18 years of age. Male-to-female ratio was 1 (62 male, 61 female). Thirty-three patients (26.8\%) had comorbid diseases including diabetes mellitus, systemic malignancies, hypothyroidism etc. The most common diagnosis in patients was mass lesions (tumor, AVM, abscess) comprising $80.5 \%$ of the study cohort. Chiari malformation (10.6\%) and congenital spinal malformation and spinal injuries (8.9\%) were other surgical indications. Of 95 patients with tumors $(77.2 \%$ of total), $57(60 \%)$ patients had benign pathology whereas the other 38 (40\%) patients had malignant neoplasms. Nineteen (15.4\%) patients had previous surgeries in the same location (revision/second surgery). Thirteen patients (10.6\%) had prior radiotherapy. Preoperative hydrocephalus was evident in 17 (13.8\%) patients.

\section{Operative Details}

Primary site of operation was cranial (infratentorial) in 77 $(62.6 \%)$ and spinal in $46(37.4 \%)$ patients. Duraplasty was needed in $54.5 \%$ of the patients, while $45.5 \%$ had primary dural closure (including small defects plugged with muscle/ periosteal graft). Of 67 patients with duraplasty, autologous grafts were used in about one-fourth (11.4\%) and xenograft or synthetic materials in the remaining three quarters $(43.1 \%)$. Fibrin sealant (Tisseel) was applied in a total of $78(63.4 \%)$ patients whereas TPD was used in 67 (54.5\%) patients. Some patients $(n=35,28.5 \%)$ had both TPD and Tisseel application while a small portion of patients $(10.6 \%)$ had none of dural sealant applications. In all cases, watertight closure was achieved as evidenced by no CSF leakage with second Valsalva maneuver after dural augmentation. Both Tisseel and TPD were well tolerated and no immediate adverse reactions were observed in patients.

\section{Postoperative Course and Complications}

Early postoperative hydrocephalus was observed radiologicallyin $20(16.3 \%)$ patients. Seven of them (35\%) had ventriculoperitoneal shunt insertion eventually. CSF fistula was detected in $13(10.6 \%)$ patients. One patient with giant vestibular schwannoma had postoperative rhinorrhea due to bony defect caused by drilling of internal acoustic meatus, but no CSF fistula through dural opening. Therefore, this patient was excluded from the group of failed dural closure/augmentation in the further analyses. Of 12 patients with failed dural closure (CSF fistula/leak), 10 had pseudomeningocele (closed CSF leak) and 2 had incisional (open) CSF leak. Pressure dressing with or without puncture was sufficient to stop CSF leak in some patients $(n=5)$ while others required further interventions: serial lumbar punctures $(n=1)$, lumbar drainage $(n=2)$, external ventricular drainage and/or ventriculoperitoneal shunt insertion $(n=2)$, wound revision for dural closure $(n=2)$. Six patients $(4.8 \%)$ had meningitis.

Table I: Demographic, Clinical and Radiological Characteristics of the Study Cohort

\begin{tabular}{|c|c|}
\hline Variable & n (\%) \\
\hline Age (years) (mean \pm SD) & $38.9 \pm 22.2$ \\
\hline \multicolumn{2}{|l|}{ Sex } \\
\hline Male & $62(50.4)$ \\
\hline Female & $61(49.6)$ \\
\hline \multicolumn{2}{|l|}{ Location } \\
\hline Cranial (posterior fossa) & $77(62.6)$ \\
\hline Spinal & $46(37.4)$ \\
\hline \multicolumn{2}{|l|}{ Diagnosis } \\
\hline Mass lesion (tumor, abscess, AVM, etc) & $99(80.5)$ \\
\hline Chiari malformation & $13(10.6)$ \\
\hline Spinal malformation or trauma & $11(8.9)$ \\
\hline \multicolumn{2}{|l|}{ Pathology } \\
\hline Benign & $85(55.3)$ \\
\hline Malignant & $38(44.7)$ \\
\hline Comorbidities & $33(26.8)$ \\
\hline Diabetes mellitus & $9(7.3)$ \\
\hline Systemic malignancy & $17(13.8)$ \\
\hline Prior radiotherapy & $13(10.6)$ \\
\hline Previous surgery & $19(15.4)$ \\
\hline Pre-operative hydrocephalus & $17(13.8)$ \\
\hline \multicolumn{2}{|l|}{ Dural closure } \\
\hline Primary closure & $56(45.5)$ \\
\hline Duraplasty with autograft & $14(11.4)$ \\
\hline $\begin{array}{l}\text { Duraplasty with xenograft/synthetic } \\
\text { material }\end{array}$ & $53(43.1)$ \\
\hline Tisseel & $78(63.4)$ \\
\hline TissuePatchDural & $67(54.5)$ \\
\hline Postoperative hydrocephalus & $20(16.3)$ \\
\hline CSF leakage & $12(9.8)$ \\
\hline \multicolumn{2}{|l|}{ CSF leak type } \\
\hline Pseudomeningocele & $9(7.2)$ \\
\hline Incisional leak & $3(2.4)$ \\
\hline Length of hospital stay (day) (mean \pm SD) & $11.0 \pm 7.2$ \\
\hline
\end{tabular}




\section{Two-Group Comparisons (TPD vs. No-TPD)}

We first compared the data of the patients receiving TPD $(n=56)$ with those not receiving TPD $(n=67)$ irrespective of their status of Tisseel use. Comparative results of two groups (TPD vs no-TPD) are given in Table II. Use of fibrin sealant (Tisseel) was significantly more common in no-TPD group $(76.8 \%$ vs $52.2 \% ; p=0.005)$. Other than this, there were no significant differences between two groups in preoperative, intraoperative and postoperative parameters. Incidences of CSF fistula were also similar between them $(10.4 \%$ vs $8.9 \%$, respectively; $\mathrm{p}=0.778$ ). When we excluded the patients with postoperative hydrocephalus from the analysis the rates dropped to $3.8 \%$ (2/52 patients) for TPD vs $4.0 \%$ (2/50 patients) for no-TPD groups, but again difference was not statistically significant.

\section{Three-Group Comparisons (Tisseelvs TPD vsTPD+Tisseel)}

We then compared the data of the patients receiving Tisseel only $(n=43)$, TPD only $(n=32)$ and TPD plus Tisseel $(n=35)$ in order to better analyze individual efficacy of two alternative sealants and also to see whether addition of fibrin sealant (Tisseel) has any effect on TPD efficacy. For this comparison, we excluded 13 patients (10.6\%) who had not received any of

Table II: Two-Group Comparison of Patients Based on Their TPD Receiving Status

\begin{tabular}{|c|c|c|c|}
\hline Variable & $\begin{array}{c}\text { TPD }(n=67) \\
n(\%)\end{array}$ & $\begin{array}{c}\text { No-TPD }(n=56) \\
n(\%)\end{array}$ & p \\
\hline Age (years) (mean \pm SD) & $39.6 \pm 22.0$ & $38.1 \pm 22.6$ & 0.724 \\
\hline \multicolumn{4}{|l|}{ Sex } \\
\hline Male & $35(52.2)$ & $27(48.2)$ & \multirow{2}{*}{0.719} \\
\hline Female & $32(47.8)$ & $29(51.9)$ & \\
\hline \multicolumn{4}{|l|}{ Location } \\
\hline Cranial (posterior fossa) & $41(61.2)$ & $36(64.3)$ & \multirow{2}{*}{0.852} \\
\hline Spinal & $26(38.8)$ & $20(35.7)$ & \\
\hline \multicolumn{4}{|l|}{ Diagnosis } \\
\hline Mass (tumor, abscess, AVM etc.) & $50(74.6)$ & $49(87.5)$ & 0.109 \\
\hline Congenital malformation and trauma & $17(25.4)$ & $7(12.5)$ & \\
\hline \multicolumn{4}{|l|}{ Pathology } \\
\hline Benign & $48(71.6)$ & $37(66.1)$ & 0.559 \\
\hline Malignant & $19(28.4)$ & $19(33.9)$ & \\
\hline Comorbidity & $17(25.4)$ & $16(28.6)$ & 0.838 \\
\hline Diabetes mellitus & $5(7.5)$ & $4(7.1)$ & 1 \\
\hline Systemic malignancy & $11(16.4)$ & $5(8.9)$ & 0.285 \\
\hline Prior radiotherapy & $9(13.4)$ & $4(7.1)$ & 0.379 \\
\hline Previous surgery & $11(16.4)$ & $8(14.3)$ & 0.806 \\
\hline Preoperative hydrocephalus & $9(13.4)$ & $8(14.3)$ & 1 \\
\hline Duroplasty & $37(55.2)$ & $30(44.8)$ & 0.858 \\
\hline \multicolumn{4}{|l|}{ Dural closure } \\
\hline Primary & $30(44.8)$ & $26(46.6)$ & \multirow{3}{*}{0.734} \\
\hline Duroplasty w autograft & $9(13.4)$ & $5(8.9)$ & \\
\hline Duroplasty w xenograft/synthetic material & $28(41.8)$ & $25(44.6)$ & \\
\hline Tisseel use & $35(52.2)$ & $43(76.8)$ & 0.005 \\
\hline Postoperative hydrocephalus & $14(20.9)$ & $6(10.7)$ & 0.148 \\
\hline CSF leakage & $7(10.4)$ & $5(8.9)$ & 0.778 \\
\hline Length of hospital stay (day) (mean \pm SD) & $11.3 \pm 7.3$ & $10.8 \pm 7.1$ & 0.692 \\
\hline
\end{tabular}


two dural sealants due to insufficient number in this subgroup. Comparative results of three groups (Tisseel vs TPD vs TPD+Tisseel) are given in Table III.

Three groups differed in distribution of diagnoses $(p=0.007)$. Non-tumoral lesions were more common in TPD+Tisseel group (34.3\%) than TPD only (15.6\%) and Tisseel only $(7.0 \%)$ groups. In addition, comorbidities were more commonly encountered in TPD only group (40.6\%) in comparison to Tisseel only (23.3\%) and TPD+Tisseel $(11.4 \%)$ group $(p=0.021)$. In a subgroup analysis, diabetes mellitus was more common in TPD only group (T: $4.7 \%$ vs TPD: $15.6 \%$ vs TPD+T: $0 \%$; $\mathrm{p}=0.027$ ) while incidences of other comorbidities including systemic malignancies (T: $4.7 \%$ vs TPD: $15.6 \%$ vs TPD+T:
17.1\%; $p=0.172$ ) were indifferent among the groups. In addition, demographics, other potential risk factors, duraplasty rates, length of hospital stay and CSF fistula rates (T: 9.3\% vs TPD: $6.3 \%$ vs TPD+T: $14.3 \% ; \mathrm{p}=0.539)$ were also similar across three groups.

\section{Predictors of CSF Fistula}

All potential factors were tested as predictors ofpostoperative CSF fistula in univariate logistic regression analysis (Table IV). Diagnosis (non-tumoral vs tumor) (OR: 3.459; 95\% Cl: 0.992-12.065; $p=0.052$ ); previous surgery (OR: 11.550; 95\% Cl: 3.165-42.152; $\mathrm{p}<0.001)$, preoperative hydrocephalus (OR: 3.769; 95\% Cl: 0.995-14.286; $p=0.051$ ); duraplasty (xenograft

Table III: Three-Group Comparison of Patients Based on Their TPD and Tisseel Receiving Status

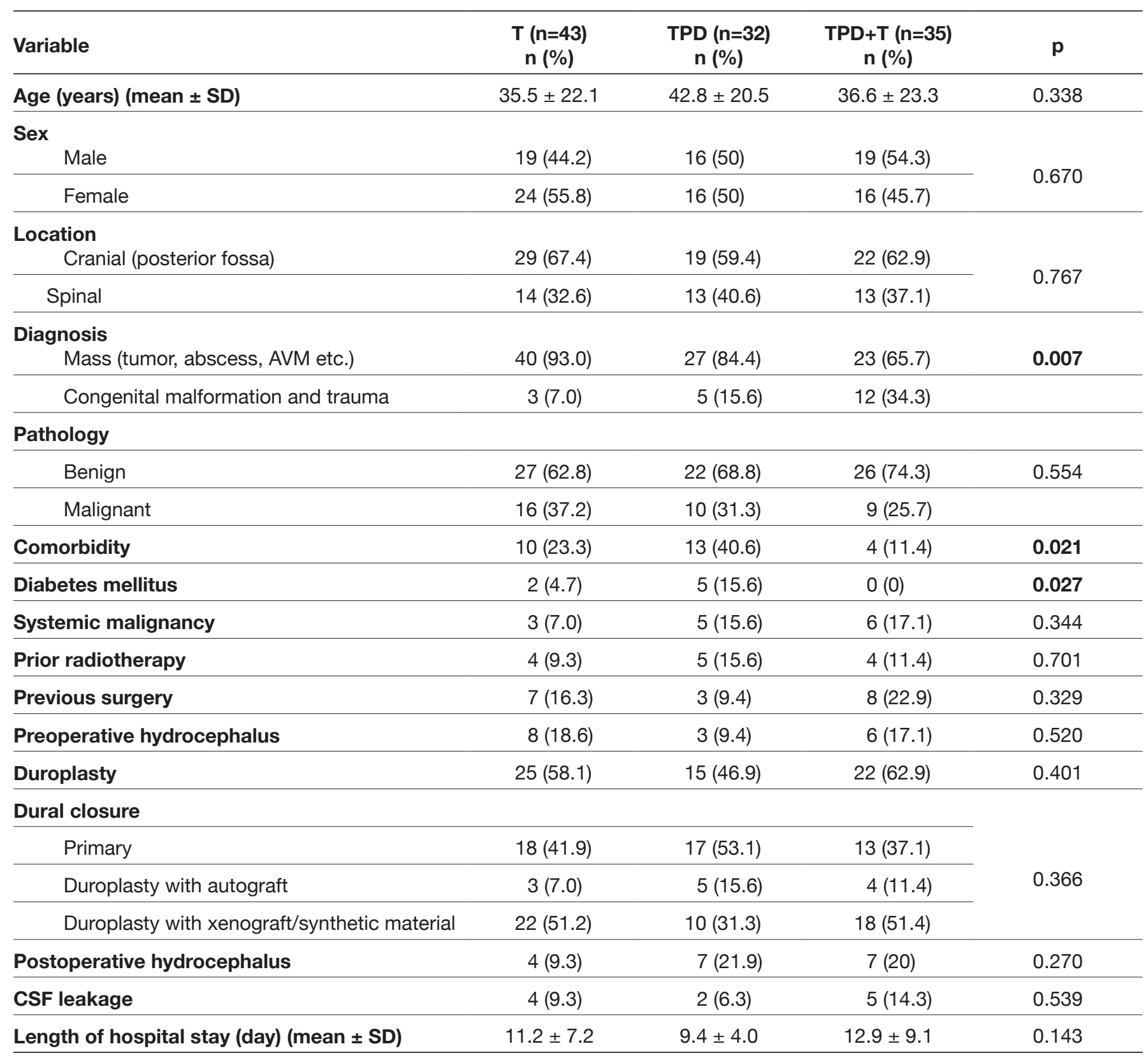


or synthetic material vs autograft or no duraplasty) (OR: 2.933; 95\% Cl: 0.833-10.327; $p=0.094)$; postoperative hydrocephalus (OR: 10.554; 95\% Cl: 2.919-38.157; $p<0.001$ ) had statistical significance $(p<0.05)$ or a trend toward significance $(p=0.05$ 0.1 ) in the univariate analyses and therefore included in multivariate analysis. Multivariate analysis revealed that diagnosis (non-tumoral vs tumor) (OR: 5.487 ; $95 \% \mathrm{Cl}$ : 1.11826.937; $p=0.036$ ); previous surgery (OR: $9.268 ; 95 \% \mathrm{Cl}: 1.911$ 44.958; $p=0.006$ ), postoperative hydrocephalus (OR: 5.456; $95 \% \mathrm{Cl}: 1.250-23.821 ; p=0.024)$ were independent predictors of postoperative CSF fistula occurrence.

\section{DISCUSSION}

Cerebrospinal fluid leakage is an important cause of morbidity (17), and even mortality after neurosurgical procedures (14). It is a relatively common (up to $30 \%$ in posterior fossa surgeries) but potentially avoidable complication $(3,10,22)$. Therefore, preventing CSF leak with watertight closure of dura mater is critical step of neurosurgical operations $(15,24,25)$. Even though there have been several studies exploring various agents and techniques, the quest for the ideal dural sealing technique continues. In recent years, many novel surgical sealants have entered the medical market and been used widely across the world despite the paucity of adequate studies validating their use in neurosurgical practice $(2,6)$. Therefore, we designed this study to compare the efficacy of a novel adhesive absorbable membrane (TissuePatchDural ${ }^{\mathrm{TM}}$ ) with a relatively more commonly used agent, fibrin glue (Tisseel), in reducing postoperative CSF leakage after posterior fossa and spinal procedures which carry higher risk of CSF leaks compared with supratentorial operations. Our study showed that their efficacy is comparable, but not additive when used in combination. Furthermore, we identified potential risk factors for CSF leakage, which seem to be associated with higher rates of CSF leaks regardless of dural sealant technique used. This is the first study in the literature that compared TPD with fibrin glue (Tisseel) and their combination in a retrospective single-center neurosurgical cohort with minimal selection bias, if any.

Various dural sealants have been shown to be safe (18), but possibly only marginally effective in reducing CSF leakage rates after neurosurgical procedures. A recent systematic review of 3682 patients from 20 studies including 3 randomized controlled trials (RCT) showed that dural sealants (both liquid and patch sealants) did not reduce the number of CSF leakage in general ( $8.2 \%$ vs $8.4 \%)$, as well as the numbers of incisional CSF leakage and pseudomeningocele alone, but reduced the risk of surgical site infection after craniotomy. They also noted that neither liquid sealants differ from sealant patches, nor fibrin glue from PEG sealants (13). Our results echo their findings by showing similar CSF leakage rates between fibrin glue (Tisseel) (9.3\%), synthetic patch (TissuePatchDural ${ }^{\mathrm{TM}}$ ) $(6.3 \%)$ and also their combination $(14.3 \%)(p=0.539)$. Interestingly, however, CSF leakage rates in TPD+Tisseel group were almost twice as high as TPD alone group, despite the fact that comorbidities including diabetes were more common in TPD alone group. The other difference between two groups wasthe primary diagnoses; non-tumoral pathologies being more common in TPD+Tisseel group. Another explanation might be the adverse effect of Tissel addition on top of TPD. This may be due to the separation of TPD margins from underlying dura after applying fibrin glue.

Table IV: Univariate and Multivariate Analyses of Potential Risk Factors for CSF Leakage After Posterior Fossa and Spinal Surgeries

\begin{tabular}{|c|c|c|c|c|}
\hline \multirow[t]{2}{*}{ Variable } & \multicolumn{2}{|l|}{ Univariate } & \multicolumn{2}{|c|}{ Multivariate } \\
\hline & OR $(95 \% \mathrm{Cl})$ & $\mathbf{p}$ & OR $(95 \% \mathrm{Cl})$ & $\mathbf{p}$ \\
\hline Age & $0.994(0.967-1.021)$ & 0.650 & & \\
\hline Sex (female) & $2.189(0.623-7.690)$ & 0.222 & & \\
\hline Location (spinal) & $0.527(0.135-2.056)$ & 0.357 & & \\
\hline Diagnosis (non-tumoral) & 3.459 (0.992-12.065) & 0.052 & 5.487 (1.118-26.937) & 0.036 \\
\hline Pathology (malignant) & $0.724(0.185-2.839)$ & 0.643 & & \\
\hline Comorbidity & $0.516(0.107-2.490)$ & 0.410 & & \\
\hline Prior radiotherapy & $1.818(0.352-9.381)$ & 0.475 & & \\
\hline Preoperative hydrocephalus & $3.769(0.995-14.286)$ & 0.051 & & \\
\hline Previous surgery & $11.550(3.165-42.152)$ & $<0.001$ & $9.268(1.911-44.958)$ & 0.006 \\
\hline Duraplasty with synthetic graft & $2.933(0.833-10.327)$ & 0.094 & $1.182(0.263-5.308)$ & 0.827 \\
\hline Tisseeluse & $1.826(0.468-7.127)$ & 0.386 & & \\
\hline TissuePatchDuraluse & $1.190(0.356-3.978)$ & 0.778 & & \\
\hline Postoperative hydrocephalus & $10.554(2.919-38.157)$ & $<0.001$ & $5.456(1.250-23.821)$ & 0.024 \\
\hline
\end{tabular}


Eser MT. et al: Dural Sealants for CSF Leakage

To the best of our knowledge this is the second largest series reporting the safety and efficacy of TPD in preventing CSF leakage. Ferroli et al. reported that CSF leakage rate was $9.2 \%$ in their retrospective series of 119 consecutive highrisk patients (supratentorial, infratentorial, spinal) in whom dura was reinforced with TPD, similarly to our studies (overall TPD group: 10.4\%) (8). Later, the same group compared two alternative dural sealing techniques (TPD vs DuraSeal) in posterior fossa surgery. In this study, they reported that postoperative CSF leak occurred in only $2.6 \%(3 / 115)$ patients in TPD group in comparison to $10.9 \%(5 / 46)$ patients in DuraSeal group $(\mathrm{p}=0.015)$. But it is of note that they excluded patients who developed postoperative hydrocephalus from this analysis. Thus, they concluded that TPD is particularly effective in patients without pre- and postoperative risk factors, in those who did not develop hydrocephalus and who underwent craniectomy (20). However, we did not exclude patients with postoperative hydrocephalus and this might be the reason why our CSF leakage rates (10.4\%) are higher than their study. In fact, when we excluded postoperative hydrocephalus from the analysis the rates dropped to $3.8 \%$ vs $4.0 \%$ in TPD and no-TPD groups, respectively. Besides, we did not compare TPD with PEG-based sealant but fibrin glue (Tisseel) and have found similar rates of CSF leakage between TPD and Tisseel group, indicating that they are equally effective, but their combination did not have additive effect in preventing postoperative CSF leaks.

Our study is the first in the literature that compared TPD with a fibrin glue. Fibrin sealants (e.g. Tisseel) have been commercially available for almost three decades $(7,21)$. Tisseel consists of human-derived fibrinogen and thrombin, and has been designed as a topical hemostatic agent to stop low level of brisk arterial and venous bleeding. As other fibrin sealants, it acts both as hemostatic and sealing agent due to its physical and chemical properties $(19,21)$. Its liquid form allows easy application, particularly in difficult-to-access areas such as ventral or lateraldural tears in spinal cases (11). However, it also has certain disadvantages including timeconsuming preparation, acute immune response in some cases, and adhesion formation and infection chronically $(9,23)$. According to the results of our study, we think that it could be preferable to use Tisseel in dural incisions/tears that are not easy to reach; but either TPD or Tisseel can be safely used in other areas to augment dural closure. Their combination, however, seems unnecessary, costly and might even have an adverse impact on CSF leakage results, therefore should be considered only in selected cases with caution.

We also investigated potential risk factors for postoperative CSF leakage after elective posterior fossa and spinal surgeries. Multivariate analysis showed that diagnosis (non-tumoral vs tumor) (OR: 5.487; 95\% Cl: 1.118-26.937; $\mathrm{p}=0.036$ ); previous surgery (OR: 9.268; 95\% Cl: 1.911-44.958; $p=0.006$ ), postoperative hydrocephalus (OR: 5.456 ; $95 \% \mathrm{Cl}$ : $1.250-$ 23.821; $p=0.024$ ) were independent predictors of postoperative CSF fistula occurrence. Postoperative hydrocephalus and previous surgery are previously demonstrated risk factors (8). However, the finding that non-tumoral cases have higher risk of development of CSF fistula is surprising and not previously shown. In a randomized controlled trial, Hutter et al. previously evaluated risk factors for postoperative CSF leakage after elective craniotomy/durotomy and found that diabetes mellitus, elevated preoperative CRP levels, and intraoperative need of a dural patch increased the risk of CSF leakage (10). However, we have found no significant effect of diabetes, prior radiotherapy, or systematic malignancy on CSF leakage rates. On the other hand, need for duraplasty with xenograft or synthetic grafts has a trend toward significance in univariate analysis, but this difference was not evident in the multivariate analysis.

The present study has certain strengths. It is the first clinical study investigating comparative effectiveness of a novel synthetic sealant patch (TPD) and a fibrin glue (Tisseel) in preventing CSF leakage after neurosurgical procedures. Authors of the study have no commercial funding or any kind of relationship with the manufacturers. The study excluded low-risk (with no cisternal or ventricular opening) and supratentorial cases, and included only posterior fossa and spinal intradural surgeries. This yielded a relatively homogenous cohort. Having similar baseline characteristics in TPD and no-TPD group as well as Tisseel, TPD and TPD+Tisseel groups also minimized effect of selection bias and allowed for fair comparisons. Rigorous statistical analysis provided not only two-group but also three-group comparisons to better dissect individual contribution of sealants in reducing CSF leakage rates in addition to identification of risk factor analysis using multivariate logistic regression.However, it has certain limitations, too. First, it is a retrospective cohort study, therefore suffers from all inherent biases of retrospective investigations. Number of patients in each group was relatively small for accurate subgroup analyses. Finally, our control group who did not receive any sealant at all was so small that this prevented us from determining whether there is a true benefit of dural sealants in prevention of CSF leaks.

\section{- CONCLUSION}

TissuePatchDural ${ }^{\mathrm{TM}}$ is a safe dural sealant patch which can be used to reinforce dural closure, either primary closure or with duraplasty, in posterior fossa and spinal intradural surgeries carrying high risk for postoperative CSF leakage. Its efficacy is comparable to widely used fibrin glue (Tisseel). However, their combination does not seem to have an additive effect, and even may have an adverse impact on the outcomes in some cases. Therefore, either TPD or Tisseel alone can be used as dural sealant based on availability and surgeryspecific factors. Furthermore, this study demonstrated that non-tumoral pathologies, previous surgery, and postoperative hydrocephalus are independent risk factors for postoperative CSF leakage and thus these factors should be carefully taken into consideration in the management of durotomies.

\section{REFERENCES}

1. Arlt F, Trantakis C, Krupp W, Renner C, Winkler D, Strauss $\mathrm{G}$, et al: Cerebro spinal fluid leak after microsurgical surgery in vestibular schwannomas viaretrosigmoidal craniotomy. Neurol Res 33:947-952, 2011 
2. Bakar B, Kose EA, Balcı M, Atasoy P, Sarkaratı B, Alhan A, Kılınc K, Keskil IS: Evaluation of the neurotoxicity of the polyethylene glycol hydrogel dural sealant. Turk Neurosurg 23:16-24,2013

3. Bryce GE, Nedzelski JM, Rowed DW, Rappaport JM: Cerebrospinal fluid leaks and meningitis in acoustic neuroma surgery. Otolaryngol Head Neck Surg 104:81-87,1991

4. Cappabianca P, Cavallo LM, Valente V, Romano I, D’Enza Al, Esposito F, et al: Sellarrepairwith fibrin sealant and collagen fleece after endoscopic endonasal transsphenoidal surgery. Surg Neurol 62:227-233, 2004

5. Cosgrove D: A complex, tissue-specific role for plasmin and its regulators in modulating fibrogenic activity. Am J Physiol Renal Physiol 293:10-11,2007

6. Della Puppa A, Rossetto M, Scienza R: Use of a new absorbable sealing film for preventing postoperative cerebrospinal fluid leaks: Remarks on a new approach. Br J Neurosurg 24:609611,2010

7. Dusick JR, Mattozo CA, Esposito F, Kelly DF: Bio Glue for prevention of postoperative cerebro spinal fluid leaks in transsphenoidal surgery: A caseseries. Surg Neurol 66:371376, 2006

8. Ferroli P, Acerbi F, Broggi M, Schiariti M, Albanese E, Tringali G: A novel impermeable adhesive membrane to reinforce dural closure: A preliminary retrospective study on 119 consecutive high-risk patients. World Neurosurg 79: 551-557,2013

9. Grotenhuis JA: Costs of postoperative cerebrospinal fluid leakage: 1-year, retrospective analysis of 412 consecutive nontraumacases. Surg Neurol 64:490-494,2005

10. Hutter G, von Felten S, Sailer MH, Schulz M, Mariani L: Risk factors for postoperative CSF leakage after elective craniotomy and the efficacy of fleece-bound tissue sealing against dural suturing alone: A randomized controlled trial: $\mathrm{J}$ Neurosurg 127:735-744,2014

11. Jankowitz BT, Atteberry DS, Gerszten PC, Karausky P, Cheng BC, Faugh R: Effect of fibrin glue on the prevention of persistent cerebral spinal fluid leakage after incidental durotomy during lumbar spinal surgery. Eur Spine J 18:1169-1174,2009

12. Kim KD, Wright NM: Polyethylenegly colhydrogel spinal sealant (Dura Seal Spinal Sealant) as an adjunct to sutured dural repair in the spine: Results of a prospective, multicenter, randomized controlled study. Spine (PhilaPa 1976) 36:19061912,2011

13. Kinacı A, Algra A, Heuts S, O’Donnell D, van der Zwan A, van Doormaal T: Effectiveness of dural sealants in prevention of csf leakageafter craniotomy: A systematic review. World Neurosurg 18:412-418,2018
14. Kumar A, Maartens NF, Kaye AH: Evaluation of theuse of BioGlue in neurosurgical procedures. J Clin Neurosci 10:661664,2003

15. Leonetti JP, Anderson D, Marzo S, Moynihan G: Prevention and management of cerebro spinal fluid fistula after transtemporal skull base surgery. Skull Base 11:87-92,2001

16. Reddy M, Schöggl A, Reddy B, Saringer W, Weigel G, Matula: A clinicalstudy of a fibrinogen-based collagen fleecefor dural repair in neurosurgery. Acta Neurochir (Wien) 144:265-269, 2002

17. Rosen DS, Wollman R, Frim DM: Recurrence of symptoms after Chiari decompression and duraplasty with nonautologous graft material. Pediatr Neurosurg 38:186-190,2003

18. Osbun JW, Ellenbogen RG, Chesnut RM, Chin LS, Connolly, PJ, Cosgrove GR, et al: A multicenter, single-blind, prospective randomized trial to evaluate the safety of a polyethylenegly colhydrogel (Duraseal Dural Sealant System) as a dural sealant in cranialsurgery. World Neurosurg 78:498-504, 2012

19. Sawamura Y, Katsuyuki A, Terasaka S: Evaluation of application techniques of fibrin sealant to prevent cerebrospinal fluid leakage: A new device for the application of aerosolized fibrin glue. Neurosurgery 44:332-337,1999

20. Schiariti M, Acerbi F, Broggi M,Tringali, G, Raggi A, Broggi G, Ferrol, P: Two alternative dural sealing techniques in posterior fossa surgery: (Polylactide-co-glycolide) self-adhesive resorbable membrane versus polyethylene glycol hydrogel. Surg Neurology Int 5:171,2014

21. Shaffrey CI, Spotnitz WD, Shaffrey ME, Jane JA: Neurosurgical applications of fibrin glue: Augmentation of dural closure in 134 patients. Neurosurgery 26:207-210,1990

22. Than KD, Baird CJ, Olivi A: Polyethyleneglycolhydrogel dural sealant may reduce incisional cerebro spinal fluid leak after posterior fossa surgery. Neurosurgery 63 (1 Suppl 1): ONS182-ONS187, 2008

23. Turgut $M$, Erkus $M$, Tavus $N$ : The effect of fibrin adhesive (Tisseel) on interbody allograft fusion: An experimental study with cats. ActaNeurochir (Wien) 141: 273-278,1999

24. Yildirim AE, Dursun E, Ozdol C, Divanlioglu D, Nacar OA, Karakoyun O, Eryilmaz A, Belen D: Using an autologous fibrin sealant in the preventing of cerebrospinal fluid leak with large skull base defect following endoscopic endonasal transsphenoidal surgery. Turk Neurosurg 23:736-741,2013

25. Yoshimoto T, Sawamura Y, Houkin K, Abe H: Effectiveness of fibrin glue for preventing postoperative extradural fluid leakage. Neurol Med Chir (Tokyo) 37:886-890,1997 